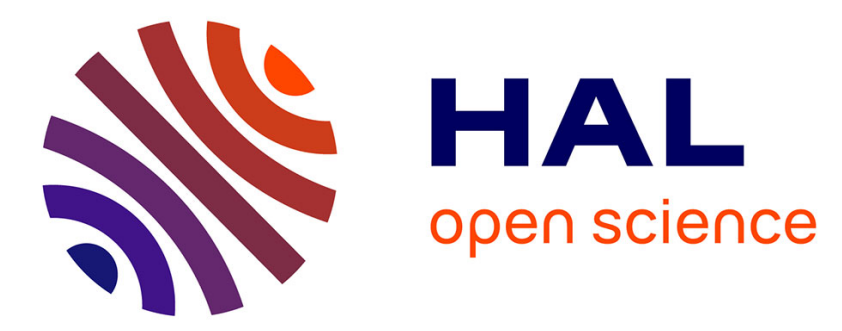

\title{
Design Optimization and Performance Evaluation of a Tillage Depth Precision Measurement System
}

\author{
Kang Niu, Yanwei Yuan, Junning Zhang, Fengzhu Wang, Yangchun Liu,
} Xianfa Fang, Hong Cheng

\section{To cite this version:}

Kang Niu, Yanwei Yuan, Junning Zhang, Fengzhu Wang, Yangchun Liu, et al.. Design Optimization and Performance Evaluation of a Tillage Depth Precision Measurement System. 10th International Conference on Computer and Computing Technologies in Agriculture (CCTA), Oct 2016, Dongying, China. pp.236-245, 10.1007/978-3-030-06155-5_23 . hal-02180006

\section{HAL Id: hal-02180006 https://hal.inria.fr/hal-02180006}

Submitted on 12 Jul 2019

HAL is a multi-disciplinary open access archive for the deposit and dissemination of scientific research documents, whether they are published or not. The documents may come from teaching and research institutions in France or abroad, or from public or private research centers.
L'archive ouverte pluridisciplinaire HAL, est destinée au dépôt et à la diffusion de documents scientifiques de niveau recherche, publiés ou non, émanant des établissements d'enseignement et de recherche français ou étrangers, des laboratoires publics ou privés. 


\title{
Design Optimization and Performance Evaluation of A Tillage Depth Precision Measurement System
}

\author{
Kang $\mathrm{Niu}^{1(\bowtie)}$, Yanwei Yuan ${ }^{1}$, Junning Zhang ${ }^{1}$, Fengzhu Wang ${ }^{1}$, Yangchun Liu ${ }^{1}$, \\ Xianfa Fang ${ }^{1}$, and Hong Cheng ${ }^{2}$ \\ ${ }^{1}$ Chinese Academy of Agricultural Mechanization Sciences, Beijing, China \\ \{niukag, yyw215\}@163.com, zhangjunning@caams.org.cn \\ wangfengzhul@126.com, lyc327@163.com, fangxf@caams.org.cn \\ ${ }^{2}$ Management Center of Agricultural Mechanization in JiLin Province, Changchun, \\ China \\ hong8868@tom.com
}

\begin{abstract}
Tillage depth measuring is essential in modernization of agricultural production, including tillage depth, seed germination, plant growth and soil conservation. At present, there are no reliable measuring method or equipment for on-line tillage depth data acquisition. To solve this problem, equipment for real-time measuring tillage depth was designed based on ultrasonic sensing technology. This system comprises mainly mechanical constructions, hardware structure, software, specific measurement process and data processing technology. To improve the measuring accuracy, Kalman filter method is used to reduce the influence of uneven surface, weed, and stubble in field. This device was installed on subsoiler, and a field test was conducted. The test results show that: The accuracy of the ultrasonic measuring depth is comparable with the manual measuring method in the field condition of ploughed field, bare field and stubble field.
\end{abstract}

Keywords: agricultural machinery, automation, tillage depth, subsoiler, real time measurement, Kalman filter

\section{Introduction}

Farming information acquisition technology is fundamental item for the development of precision agricultural technology. Real time measuring system of tillage depth is a prerequisite for the development of precision agriculture production [1-3]. Nowadays, tillage depth measuring is a basic item of soil cultivation, sowing and planting. Effects of tillage depth accuracy are crucial on soil cultivation, seed germination and seeding growth [4-5].

To measure tillage depth directly, the traditional manual measurement method is inserting a depth meter to groove bottom, which is labor-demanding and costprohibiting for large-scale data acquisition. At present, common methods for real time tillage depth measuring method can be divided into two kinds, direct measurement and indirect measurement [6-9]. The direct method is based on a replicated wheel or sliding palm. Usually, a replicated part is mounted to agricultural implement. The position change in valve between the replicated part and the mounted implement can be measured, which is equal to the tillage depth. Another is indirect measurement method, which integrated sensor, such as inclinometer, is mounted on surface of lower lifting arm. Compared to direct method, indirect method is more convenient to be installed. However, the accuracy of indirect measuring method is easy interfered by environment. Hence, the direct measuring method is more reliable [10-15].

At first, we mounted an ultrasonic sensor on a framework to measure distance to the ground. The ultrasonic sensor generates a sound signal and received it after reflection of ground. However, available measuring data are hardly acquired as field condition is complex. The main influence factors includes uneven field surface, weeds, crop 
residue and etc. Therefore, we designed a parallelogram mechanism to solve this problem.

This paper describes a technique to monitor working depth of a subsoiler. The device includes an ultrasonic sensor and a vertical reference plane to measure a horizontal distance between the sensor and the vertical reference plane. According to the change of horizontal distance, a parallel linkage is utilized to estimate the vertical distance between the soil surface and the subsoiler engagement below the soil surface. To improve the ranging accuracy, a Kalman filtering method is used to decrease the influenced by factors like uneven farmland, weeds and crop residue.

\section{Experimental Device and Methods}

\subsection{Outline of experimental device}

Experimental device consists of five main parts: power supply unit 1, acousto-optic alarm 2, vehicle display terminal 3, ultrasonic sensor 4 and mechanic device 5 as shown in Figure 1. The actual depth was calculated by signals from ultrasonic sensor.

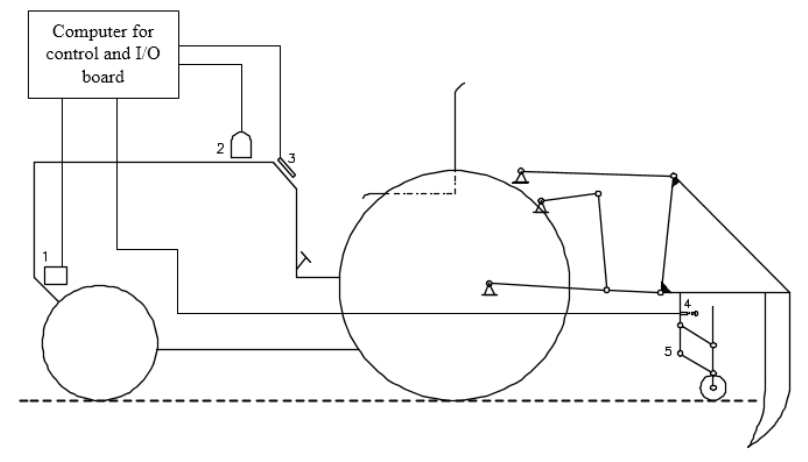

Fig. 1. Schematic diagram of experimental device

1. Power supply unit 2. Acousto-optic alarm 3. Vehicle display terminal 4. Ultrasonic sensor 5.Mechmatic device

\subsubsection{Mechanical System Design}

The structure diagram of the parallelogram is shown in Figure 2.

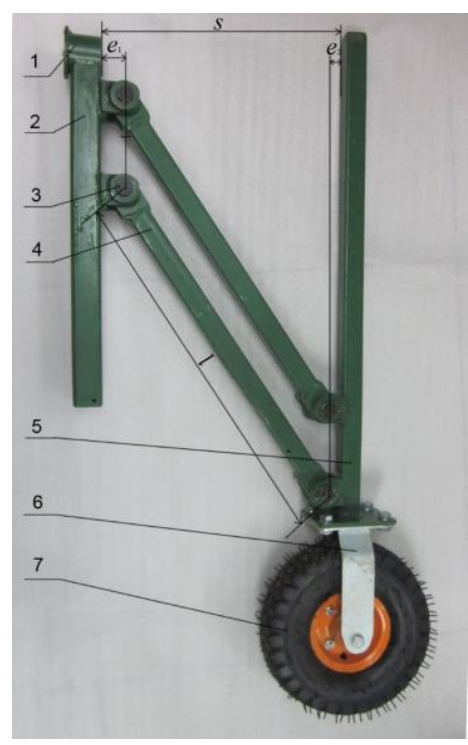

Fig. 2. Structure of displacement measurement system bracket 7. Land wheel. 
Mechanical structure of measurement system consists mainly 7 parts, possessing relatively independent integrity structure, which is bolted to a main beam through main bracket 2 . Main bracket 2 is fixed in the position of vertical direction with the measured machine. Influence by swing link 4, reflection bar is able to keep vertical all along. Thus, reflection bar 5 is always parallel to main bracket 2 . While land wheel rolls in field, reflection bar 5 remains perpendicular to the direction of ultrasonic signal all the time, ensuring ultrasonic transmitter receiving the returned signal stable and reliable.

\subsubsection{Hardware Design}

The hardware system is mainly composed of ultrasonic sensor 1 , controller 2 and vehicle display terminal 3. The photo of designed hardware is shown in Figure 3.

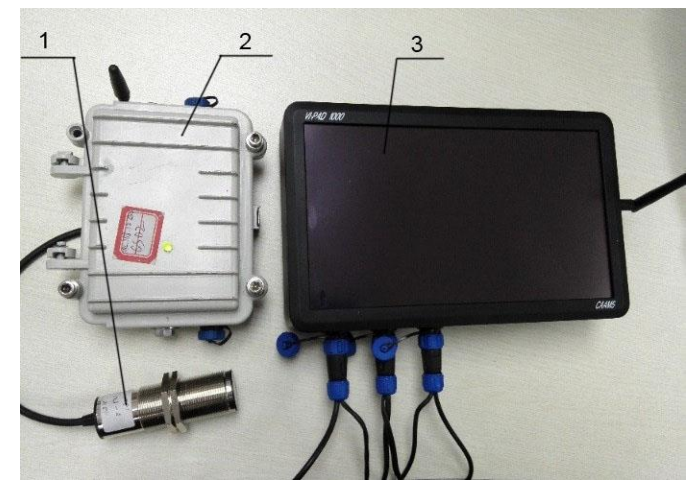

Fig. 3. System hardware

1. Ultrasonic sensor 2. Controller 3. Vehicle display terminal.

\subsection{System initialization and calibration}

Geometrical relationship between tillage depth and sensor measurements is shown in Figure 4 . The principles of calculation determining method are as follows.

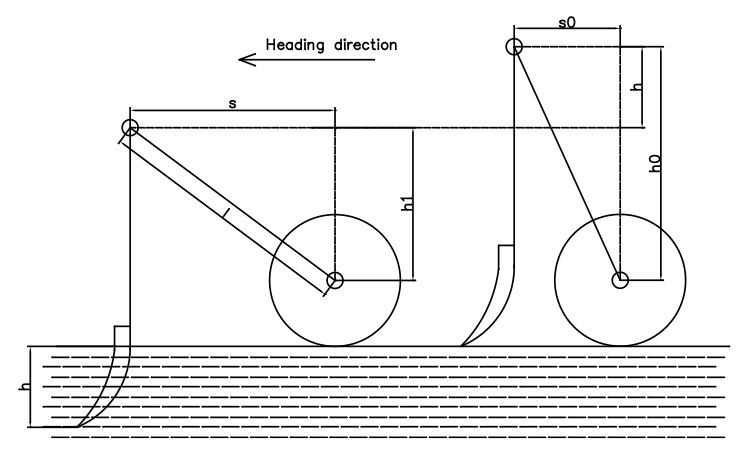

Fig. 4. Structure of displacement measurement

Ahead of the field operation, the distance of the ultrasonic transmitter and the refection plane was recorded as $s_{0}$. The corresponding vertical distance is $h_{0}$.

$$
h_{0}=\sqrt{l^{2}-s_{0}^{2}}
$$

Where $l$ is the rod length, mm.

In processing of field operations, vertical distance between land wheel and mounted point is varying in real time. The change value is equal to tillage depth $h$. The direct measured value $s$ is distance between sensor and reflection plane. According to geometric relationships between the parts, a tillage depth formula is advised.

$$
h=h_{0}-h_{1}=\sqrt{l^{2}-s_{0}^{2}}-\sqrt{l^{2}-s^{2}}
$$

For the purpose of adapting the differences of measured equipment and operating standards, both rod length and ground clearance are adjustable. It is beneficial to improve measurement accuracy and protect measuring mechanism to increase ground clearance. Meanwhile, measurement range will be limited. Considering machining 
accuracy, two initialization parameters are defined to correct this system, which are location allowance and mounting distance. Thus, four parameters are used to initialize this system.

The effective length of parallelogram mechanism is defined as the rod length $l$. In position of tillage depth zero, the clearance of ground wheel and the ground is defined as ground clearance $c$. In order to reduce the error caused by the machining error, location allowance $e$ is defined. The calibration method is described as follows: turning the parallelogram mechanism to full travel can be achieved. The valves are calculated with the following formula.

$$
\begin{gathered}
e=e_{1}+e_{2} \\
e=\max (s)-l \\
s_{0}=\min (s)-e
\end{gathered}
$$

The tillage depth formula is revised as shown below.

$$
h=\left\{\begin{array}{c}
c+\sqrt{l^{2}-s_{0}^{2}}-\sqrt{l^{2}-(s-e)^{2}}, h>c+2 \\
0, h \leq c+2
\end{array}\right.
$$

\subsection{Data processing method}

The designed parallelogram mechanism reduced the influence of field factors including weeds, crop residue and uneven surface, but the measuring data is still fluctuating, which cannot reflect actual situation. Thus, Kalman filter method is used for data processing. For dynamic data, Kalman filter is useful to get a relative smooth trajectory of the sensor. The Kalman filter uses a system's dynamics model to form an estimate of the system's varying quantities that is better than the estimate obtained by using any one measurement alone. It is a common sensor fusion and data fusion algorithm.

\subsection{Experimental method}

In field, the measuring device is mounted on a subsoiler as shown in Figure 5.

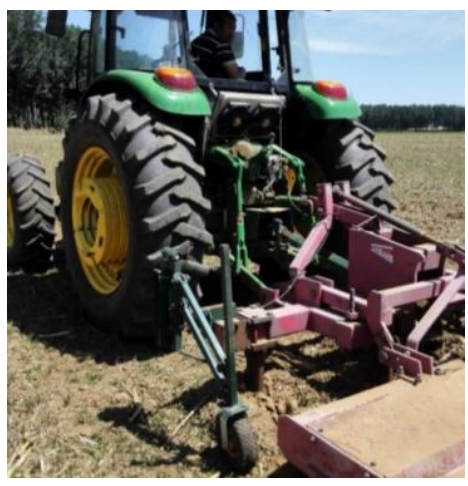

Fig. 5. Real time precision measurement system

The measuring device is mounted on a subsoiler as shown in Figure 5. The tractor is John Deere 1204. The working width is $2 \mathrm{~m}$. The normal travel speed is $2 \mathrm{~m} / \mathrm{s}$. The device is driven by a tractor, and the power supply is a storage battery, which is mounted on tractor and charged by tractor engine.

\section{Results and discussion}

\subsection{Kalman filter}

In condition of bare field, travel speed $2 \mathrm{~m} / \mathrm{s}$, target tillage depth $35 \times 10^{-2} \mathrm{~m}$. The comparison between the censor output and the result of Kalman filter is shown in Figure 6 . The test results proved that this combination of parameters settings can suppress high power narrow band interference effectively, and avoids the data distortion, which has enhanced adaptive ability in complex field environment. 


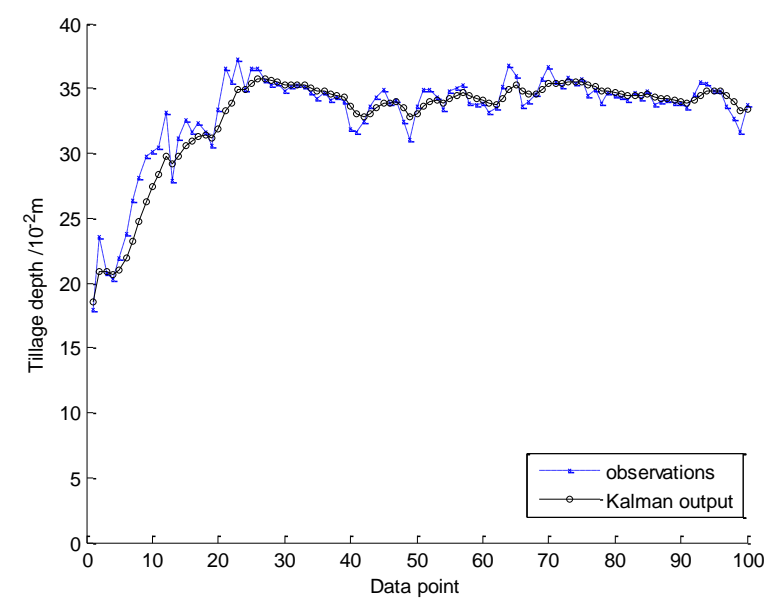

Fig. 6. Comparisons between the censor output and the result of Kalman filter

\subsection{Comparison experiment of different target}

Under the experiment condition of bare land and travel speed of $2 \mathrm{~m} / \mathrm{s}$, the results of automatic measuring and manual measuring of different target tillage depth are shown in Figure 7.

The measuring results show that deeper tillage working depth is beneficial to stability of tillage depth. Comparison curve between the automatic measuring and the manual measuring show that the differences among the automatic measuring data is smaller, which is contributed by Klaman filter. However, in consider of the field complex condition, these errors can be ignored and the Kalman filter results are acceptable. Measuring accuracy increases with the increasing of tillage depth. The measuring accuracy are $1.04 \times 10^{-2} \mathrm{~m}, 0.66 \times 10^{-2} \mathrm{~m}$ and $0.51 \times 10^{-2} \mathrm{~m}$, while the tillage depth are $20 \times 10^{-2} \mathrm{~m}, 30.0 \times 10^{-2} \mathrm{~m}$ and $40 \times 10^{-2} \mathrm{~m}$.

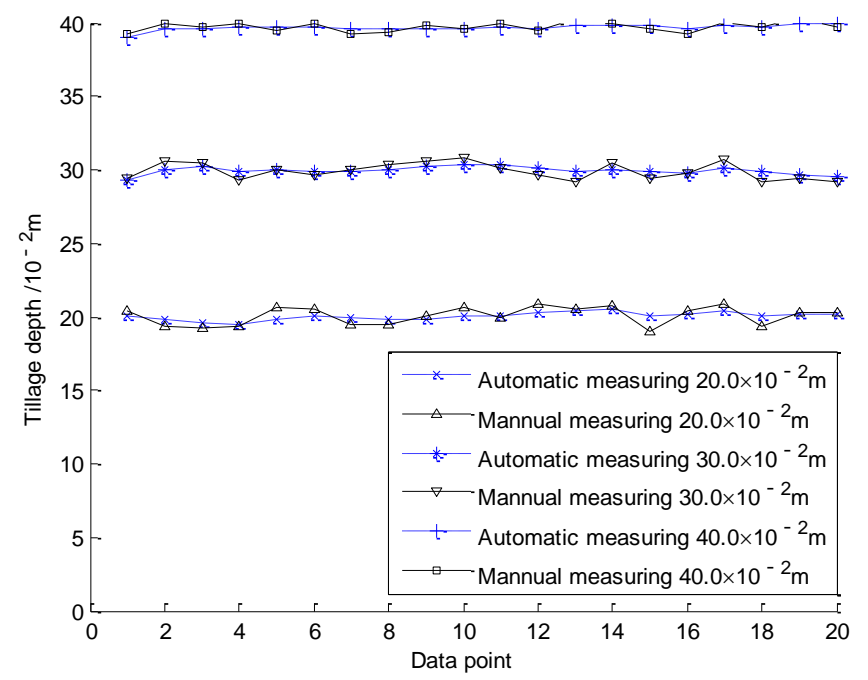

Fig. 7. The measuring results of different tillage depth

\subsection{Comparison experiment of different field types}

Under the experiment condition of travel speed $2 \mathrm{~m} / \mathrm{s}$ and target tillage depth of $30 \times 10^{-}$ ${ }^{2} \mathrm{~m}$, the results of automatic measuring and manual measuring of different field conditions are shown in Figure 8. 


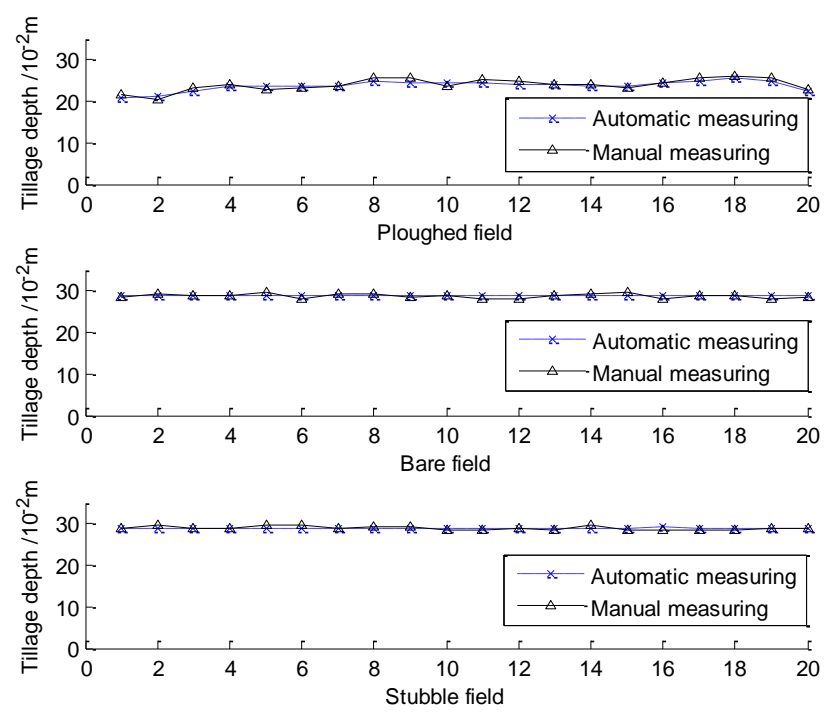

Fig. 8. Measuring results of different field conditions

As can be seen from the results, in bare field and stubble field, tillage depth is stable and well in consistency, with high measuring accuracy of $0.74 \times 10^{-2} \mathrm{~m}$ and $0.6 \times 10^{-2} \mathrm{~m}$ respectively. In contrast, the tillage depth is unstable in ploughed field, with measuring accuracy of $1.14 \times 10^{-2} \mathrm{~m}$. In bare field with smooth surface, tillage depth measuring have a good condition, which is benefit to depth measurement. While the field with weeds, straw or stubble, surface profiling mechanism can eliminate the disturbance partially. The measuring system can provide depth detection effectively with a high detection percentage and the error can be accepted.

\subsection{Comparison experiment of different target tillage depth}

In bare land, with the target tillage of $30 \times 10^{-2} \mathrm{~m}$, the results of automatic measuring and manual measuring of different travel speed is shown in Figure 9.

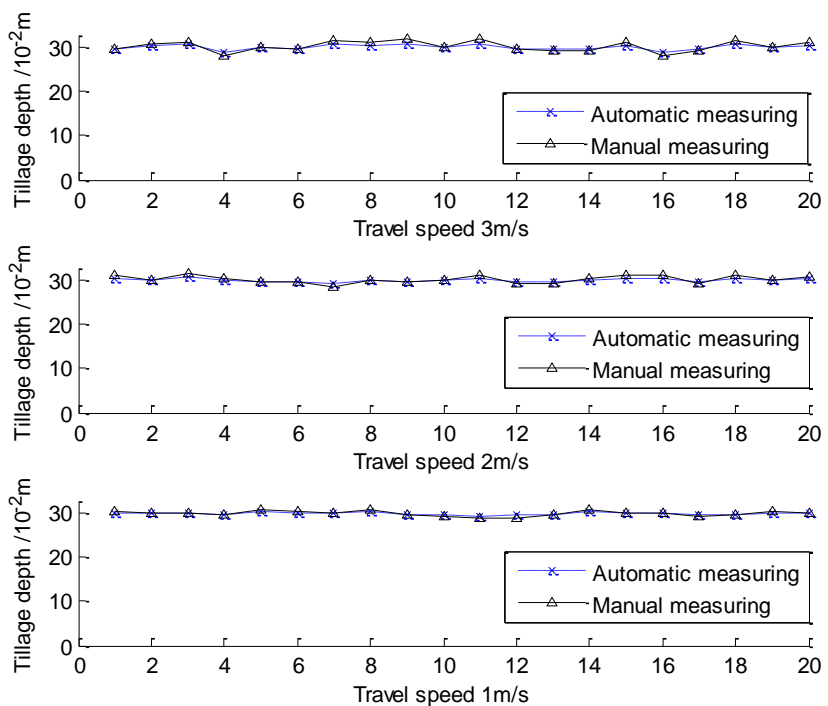

Fig. 9. The measuring results of different travel speed

The measuring results of three speed show that the measuring accuracy decreases with the increasing of travel speed. While operating speed are $1 \mathrm{~m} / \mathrm{s}, 2 \mathrm{~m} / \mathrm{s}$ and $3 \mathrm{~m} / \mathrm{s}$, the measuring accuracy are $0.5 \times 10^{-2} \mathrm{~m}, 0.74 \times 10^{-2} \mathrm{~m}$ and $1 \times 10^{-2} \mathrm{~m}$, respectively. 
In most area of China, the deep loosening target depth is $25-35 \times 10^{-2} \mathrm{~m}$, and the working speed is generally $1-2 \mathrm{~m} / \mathrm{s}$, with bare land or stubble field. Overall, this monitor device can be used in tillage depth measuring of subsoiler.

\section{Conclusions}

A monitor system for tillage depth measurement is designed based on the ultrasonic technology. The monitor device includes an ultrasonic sensor and a vertical reference plane to measure a horizontal distance between the sensor and the vertical reference plane. A Kalman filtering method is used to improve the measuring accuracy.

The test results shows that: while the tillage depth are $20 \times 10^{-2} \mathrm{~m}, 30.0 \times 10^{-2} \mathrm{~m}$ and $40 \times 10^{-2} \mathrm{~m}$, the measuring accuracy are $1.04 \times 10^{-2} \mathrm{~m}, 0.66 \times 10^{-2} \mathrm{~m}$ and $0.51 \times 10^{-2} \mathrm{~m}$ respectively; in field condition of bare, stubble and ploughed, the measuring accuracy are $0.74 \times 10^{-2} \mathrm{~m}, 0.6 \times 10^{-2} \mathrm{~m}$ and $1.14 \times 10^{-2} \mathrm{~m}$ respectively; while operating speed are 1 $\mathrm{m} / \mathrm{s}, 2 \mathrm{~m} / \mathrm{s}$ and $3 \mathrm{~m} / \mathrm{s}$, the measuring accuracy are $0.5 \times 10^{-2} \mathrm{~m}, 0.74 \times 10^{-2} \mathrm{~m}$ and $1 \times 10^{-2} \mathrm{~m}$, respectively.

The accuracy of the ultrasonic measuring depth is comparable with the manual measuring method in the field condition of ploughed field, bare field and stubble field.

\section{Acknowledgment}

Funds for this research was provided by the National Key research and development Plan Projects (2017YFD0700101, 2017YFD0700205,). The author acknowledges the co-operation of Chinese Academy of Agricultural Mechanization Sciences and College of Engineering in China Agricultural University for their assistance.

\section{References}

1. Lee Jeyong, Yamazaki M, Oida A, et al. Field performance of proposed foresight tillage depth control system for rotary implements mounted on an agricultural tractor [J]. Journal of Terramechanics, 2000, 37(2): 99-111.

2. Mouazen A M, Anthonis J, Saeys W, et al. An automatic depth control system for real time measurement of spatial variation in soil compaction, part 1: sensor design for measurement of frame height variation from soil surface [J]. Biosystems Engineering, 2004, 89(2): 139 -150 .

3. Wu Weixiong, Ma Rongchao. Design of the automatic control of the plowing depth of the integrated plowing set [J]. Journal of Agricultural Mechanization Research, 2007(9): $77-$ 79. (In Chinese)

4. Li Ling, Li Jiangquan, Li Xingrong, et al. Design researches on tiling depth electron testing system[J], Journal of Shihezi University: Natural Science, 2001,5(3): 246-248. (In Chinese)

5. Singh C D, Singh R C. Computerized instrumentation system for monitoring the tractor performance in the field [J]. Journal of Terramechanics, 2011, 48(5): 333-338.

6. Bentaher H, Hamza E, Kantchev G, et al. Three-point hitch-mechanism instrumentation for tillage power optimization [J]. Biosystems Engineering, 2008, 100(1):24-30.

7. Du Qiaolian, Xiong Xicheng, Wei Jianhua. Design and experiment on the control system of electro-hydraulic plow depth of tractor hydraulic hitch mechanism [J].Transactions of the Chinese Society for Agricultural Machinery, 2008, 39(8): 62-65. (In Chinese)

8. Li Qing, Luo Xiwen, Wang Maohua, et al. Design of a laser land leveler for paddy field [J]. Transactions of the Chinese Society of Agricultural Engineering (Transactions of the CSAE), 2007, 23(4): 88-93. (In Chinese)

9. Yahya A, Zohadie M, Kheiralla A F, et al. Mapping system for tractor-implement performance Computers and Electronics in Agriculture[J]. 2009, 69 (1): 2-11.

10. Xie Bin, Li Hao, Zhu Zhongxiang, et al. Measuring tillage depth for tractor implement automatic using inclinometer [J]. Transactions of the Chinese Society of Agricultural Engineering (Transactions of the CSAE), 2013, 29(4): 15-21. (In Chinese)

11. Mouazen, A.B., Ramon, H. Development of on-line measurement system of bulk density based on on-line measured draught, depth and soil moisture content. Soil and Tillage Research. 2006, 86(2), 218-229.

12. Speckmann H, Jahns G. Development and application of an agricultural BUS for data transfer. Computers and Electronics in Agriculture. 1999, 23(3): 219-237. 
13. Andrew J. Scarlett. Integrated control of agricultural tractors and implements: a review of potential opportunities relating to cultivation and crop establishment machinery. Computers and Electronics in Agriculture. 2001, 30:167-191.

14. Jeyong Lee, M.Yamazaki, A.Oida, H.Nakashima, H.Shimizu. Field performance of proposed foresight tillage depth control system for rotary implements mounted on an agricultural tractor. Journal of Terramechanics. 2000, 37(2), 99-111.

15. Tractors and Machinery for Agriculture and Forestry-Serial Control and Communications Data Network-VirtualTerminal. ISO11783-6 . 